Bull. Chem. Soc. Ethiop. 2020, 34(1), 67-74.

ISSN 1011-3924

(c) 2020 Chemical Society of Ethiopia and The Authors

Printed in Ethiopia

DOI: https://dx.doi.org/10.4314/bcse.v34i1.6

\title{
HEXAVALENT CHROMIUM REDUCTION FROM REAL ELECTROPLATING WASTEWATER BY CHEMICAL PRECIPITATION
}

\author{
Bharti Verma* and Chandrajit Balomajumder
}

Department of Chemical Engineering, IIT Roorkee, Roorkee, India 247667

(Received May 9, 2019; Revised October 17, 2019; Accepted December 22, 2019)

\begin{abstract}
The immense use of chromium in the electroplating process leads to the discharge of hexavalent chromium in its effluent. Since Cr(VI) is highly toxic, its exposure poses an acute risk of health. On the contrary, $\mathrm{Cr}(\mathrm{III})$ which is naturally occurring, is much less toxic than $\mathrm{Cr}(\mathrm{VI})$. Therefore the easiest way to deal with $\mathrm{Cr}(\mathrm{VI})$ is to reduce it into its trivalent form. Exhaustive chemical analysis was done to reduce $\mathrm{Cr}$ (VI) to $\mathrm{Cr}$ (III) by using sodium metabisulfite $\left(\mathrm{Na}_{2} \mathrm{~S}_{2} \mathrm{O}_{5}\right)$ and ferrous sulfate $\left(\mathrm{FeSO}_{4}\right)$. And after the reduction process, precipitating agents such as $\left(\mathrm{Ca}(\mathrm{OH})_{2}\right),(\mathrm{NaOH})$ and a combination of the two were used to precipitate $\mathrm{Cr}(\mathrm{III})$ as hydroxides. Various parameters were varied and optimized. It was observed that the $\% \mathrm{Cr}(\mathrm{VI})$ reduction increased from $88 \%$ to $99.97 \%$ when the dosage of sodium metabisulfite increased from $40 \mathrm{mg} / \mathrm{L}$ to $100 \mathrm{mg} / \mathrm{L}$ at a $\mathrm{pH}$ of 2 . The maximum removal of $98.2 \%$ was achieved by using the combination of $\mathrm{Ca}(\mathrm{OH})_{2}+\mathrm{NaOH}$ at a pH of 9 .
\end{abstract}

KEY WORDS: Hexavalent chromium, Electroplating, Heavy metal, Chemical precipitation, Wastewater treatment

\section{INTRODUCTION}

The enormous application of heavy metals in almost all industries has led to the presence of these toxic heavy metals in industrial effluents beyond their tolerance limit [1]. Due to their nonbiodegradability, they keep accumulating in living organisms and pose a threat to their existence by causing chronic disorders [2]. The maximum concentration limits of heavy metals which are acceptable are given in Table 1. Beyond these maximum concentrations, the presence of heavy metals is highly detrimental and leads to life-threatening diseases such as cancer, asthma, brain damage, kidney damage, liver damage, and may even lead to death [3]. Of all the obnoxious heavy metals, hexavalent chromium is one such metal that is widely employed in a vast variety of industrial applications [4]. It is utilized in industries such as in electroplating, stainless steel industries, leather tanning, wood preservation processes, dye, cement and photography industries [5]. According to US EPA, Cr(VI) is recognized as one of the 17 most toxic and lifethreatening elements [6]. Long term exposure to a hexavalent form of chromium causes severe damage to both flora as well as fauna. It might be a cause for diseases such as pulmonary congestions, allergic dermatitis, severe diarrhea, etc [7]. Due to the toxicity of $\mathrm{Cr}(\mathrm{VI})$, it becomes a major threat to the environment [8]. Unlike $\mathrm{Cr}(\mathrm{VI}), \mathrm{Cr}(\mathrm{III})$ is less mobile, stable and relatively nontoxic. $\mathrm{Cr}(\mathrm{VI})$ is almost 300 times more toxic than $\mathrm{Cr}(\mathrm{III})$ [9]. The maximum concentration limit for $\mathrm{Cr}(\mathrm{VI})$ is not more than $0.05 \mathrm{mg} / \mathrm{L}[10,11]$. However, the industrial wastewater contains concentrations that are beyond the permissible limit. Some of the heavy metals can be easily removed from the solution as they precipitate readily as insoluble hydroxides in a highly alkaline medium. Therefore, wastewater containing heavy metal is treated with lime, fly ash, or any other alkaline material [12]. However, $\mathrm{Cr}(\mathrm{VI})$ forms a chromate complex and does not behave as insoluble hydroxide. Therefore, it is inevitable to reduce $\mathrm{Cr}(\mathrm{VI})$ to $\mathrm{Cr}(\mathrm{III})$ which is presumably thought of as harmless in comparison to $\mathrm{Cr}(\mathrm{VI})$.

*Corresponding author. E-mail: bverma@ch.iitr.ac.in

This work is licensed under the Creative Commons Attribution 4.0 International License 
Table 1. Maximum concentration limits of various heavy metals [12].

\begin{tabular}{|l|l|}
\hline Heavy metal & MCL (mg/L) \\
\hline Lead & 0.006 \\
\hline Copper & 0.25 \\
\hline Arsenic & 0.05 \\
\hline Chromium & 0.05 \\
\hline Nickel & 0.20 \\
\hline Zinc & 0.80 \\
\hline
\end{tabular}

Several heavy metal treatment methods such as reduction and precipitation [13], ion exchange [14], electrolysis [15], membrane filtration [16], adsorption [17, 18], and biological treatment [19] have been suggested in literature. Unlike other technologies such as membrane technology which is a highly energy consuming process, chemical precipitation does not require any energy inputs, is easier to operate and the technology is quite cheap [20]. Besides, chemical precipitation is the most effective of all the technologies and the separation of precipitates from the water can be achieved easily by sedimentation or filtration [21, 22]. Therefore, it is the most widely employed technique for the removal of obnoxious heavy metals, i.e. $\mathrm{Cr}(\mathrm{VI})$ is reduced to $\mathrm{Cr}(\mathrm{III})$ at a lower $\mathrm{pH}$ and precipitation of $\mathrm{Cr}(\mathrm{OH})_{3}$ at a higher $\mathrm{pH}$. Some authors have reported $\mathrm{Cr}(\mathrm{VI})$ reduction by ferrous pentacarbonyl [23], hydrazine [24], Zero-valent iron [25], carboxymethyl cellulose-stabilized zero-valent iron nanoparticles [26] as well as ferric chloridepolymer combination [27]. However, the application of sodium metabisulfite and ferrous sulfate is the most economically feasible of all the reducing agents explored in the literature [28].

The present study focuses on the reduction of hexavalent chromium present in electroplating wastewater to trivalent chromium using reducing agents such as sodium metabisulfite and ferrous sulfate and then precipitating the $\mathrm{Cr}(\mathrm{III})$ hydroxides using precipitating agents such as $\mathrm{NaOH}$ and $\mathrm{Ca}(\mathrm{OH})_{2}$.

\section{EXPERIMENTAL}

Analysis of electroplating wastewater

The electroplating effluent used in this study is taken from B.E.L, Kotdwar, Uttarakhand, India. The effluent was analyzed for its various heavy metals, cations, and anions by the use of induction coupled plasma-mass spectroscopy (ICP-MS) and ion chromatography (IC), respectively. The characterization was performed at the Institute Instrumentation Center, Indian Institute of Technology, Roorkee, India.

\section{Batch reduction experiment}

Batch reduction experiments were performed in $200 \mathrm{~mL}$ Erlenmeyer flasks in an incubator maintained at a constant temperature. The contents of the flask were thoroughly mixed by maintaining the speed constant. Sodium metabisulfite, when added to water, forms sodium bisulfate by the following equation:

$\mathrm{Na}_{2} \mathrm{~S}_{2} \mathrm{O}_{5}+\mathrm{H}_{2} \mathrm{O} \stackrel{\text { yields }}{\longrightarrow} 2 \mathrm{NaHSO}_{3}$

Sodium bisulfite and ferrous sulfate reduce $\mathrm{Cr}(\mathrm{VI})$ to $\mathrm{Cr}(\mathrm{III})$ by the following equations:

$\mathrm{H}_{2} \mathrm{Cr}_{2} \mathrm{O}_{7}+3 \mathrm{NaHSO}_{3}+3 \mathrm{H}_{2} \mathrm{SO}_{4} \stackrel{\text { yields }}{\longrightarrow} \mathrm{Cr}_{2}\left(\mathrm{SO}_{4}\right)_{3}+3 \mathrm{NaHSO}_{4}+4 \mathrm{H}_{2} \mathrm{O}$ 
$\mathrm{H}_{2} \mathrm{Cr}_{2} \mathrm{O}_{7}+6 \mathrm{FeSO}_{4}+6 \mathrm{H}_{2} \mathrm{SO}_{4} \stackrel{\text { yields }}{\longrightarrow} \mathrm{Cr}_{2}\left(\mathrm{SO}_{4}\right)_{3}+3 \mathrm{Fe}_{2}\left(\mathrm{SO}_{4}\right)_{3}+7 \mathrm{H}_{2} \mathrm{O}$

In the batch reduction experiment, several runs were executed on varied $\mathrm{pH}$ (1.5 to 3.5) to achieve the most optimum $\mathrm{pH}$ of the solution. For each $\mathrm{pH}$, the dosage of both reducing agents was varied (500 to $1100 \mathrm{mg} / \mathrm{L}$ for ferrous sulfate and 40 to $100 \mathrm{mg} / \mathrm{L}$ for sodium metabisulfite) for the same set of conditions to evaluate the effect of dosage on the reduction process. Since $\mathrm{Cr}(\mathrm{VI})$ behaves highly oxidizing in a low $\mathrm{pH}$, therefore reduction is carried out in an acidic medium. All the $\mathrm{pH}$ adjustments are done by using $0.05 \mathrm{M} \mathrm{H}_{2} \mathrm{SO}_{4}$ and $0.1 \mathrm{M} \mathrm{NaOH}$.

Chemical precipitation

After $\mathrm{pH}$ adjustment (to around 9), the dissolved metal ions are converted to the insoluble solid phase via a chemical reaction with a precipitating agent. The mechanism behind the precipitation of heavy metal as insoluble hydroxides via chemical precipitation can be explained by the following equation:

$\mathrm{M}^{2+}+2(\mathrm{OH})^{-} \leftrightarrow M(\mathrm{OH})_{2} \downarrow$

where $\mathrm{M}^{2+}$ is the metal ion; $\mathrm{OH}^{-}$comes from the precipitant and $\mathrm{M}(\mathrm{OH})_{2}$ represents the insoluble metal hydroxide. The precipitation reactions by using $\mathrm{NaOH}$ and $\mathrm{Ca}(\mathrm{OH})_{2}$ are as follows:

$\mathrm{Cr}_{2}\left(\mathrm{SO}_{4}\right)_{3}+3 \mathrm{NaOH} \stackrel{\text { yields }}{\longrightarrow} 2 \mathrm{Cr}(\mathrm{OH})_{3}+3 \mathrm{Na}_{2} \mathrm{SO}_{4}$

$\mathrm{Cr}_{2}\left(\mathrm{SO}_{4}\right)_{3}+3 \mathrm{Ca}(\mathrm{OH})_{2} \stackrel{\text { yields }}{\longrightarrow} 2 \mathrm{Cr}(\mathrm{OH})_{3}+3 \mathrm{CaSO}_{4}$

Analysis of hexavalent chromium

The concentration of $\mathrm{Cr}(\mathrm{VI})$ was determined spectrophotometrically by the diphenylcarbazide method [29]. The wavelength was kept at around $540 \mathrm{~nm}$.

Analysis of total chromium

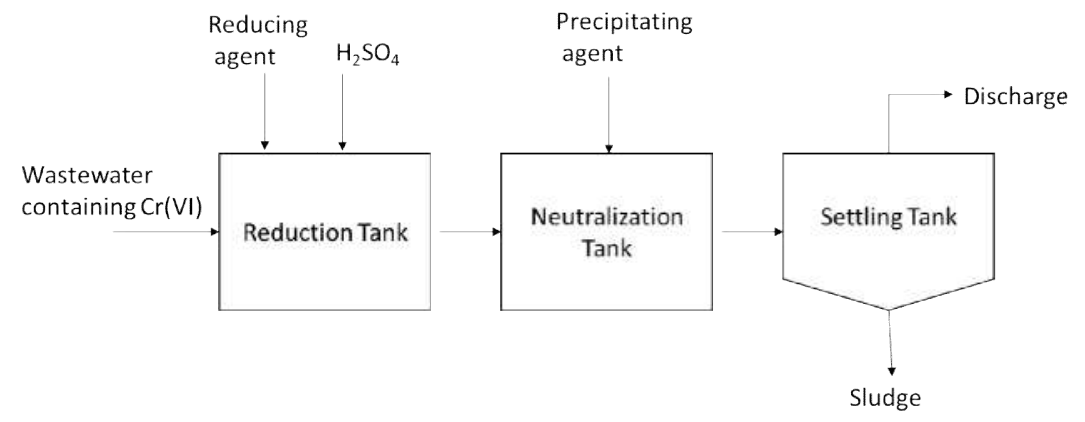

Figure 1. Schematic diagram of process.

The total chromium was analyzed by inductively coupled plasma mass spectroscopy at Institute Instrumentation Center, IIT Roorkee, Roorkee, India. The $\mathrm{Cr}(\mathrm{III})$ was evaluated by subtracting 
$\mathrm{Cr}(\mathrm{VI})$ from total chromium. The schematic diagram of the whole process of reduction and precipitation is elaborated in Figure 1.

\section{RESULTS AND DISCUSSION}

\section{Characteristics of effluent}

The electroplating effluent was analyzed for its constituents by ICP-MS and the characteristics are given in Table 2. Since the chrome plating uses chromium trioxide in an acidic environment, the $\mathrm{pH}$ of the effluent is quite low and the concentration of hexavalent chromium is quite high.

Table 2. Characteristics of electroplating effluent.

\begin{tabular}{|c|c|}
\hline Parameter & Value $(\mathrm{mg} / \mathrm{L})$ \\
\hline TDS & 4300 \\
\hline $\mathrm{pH}$ & 2.02 \\
\hline $\mathrm{Cr}(\mathrm{VI})$ & 122 \\
\hline $\mathrm{Ni}$ & 11.3 \\
\hline $\mathrm{Al}$ & 10.4 \\
\hline $\mathrm{Fe}$ & 3 \\
\hline $\mathrm{Cu}$ & 2 \\
\hline Nitrate & 8.92 \\
\hline As & 0.2 \\
\hline
\end{tabular}

Optimization of parameters

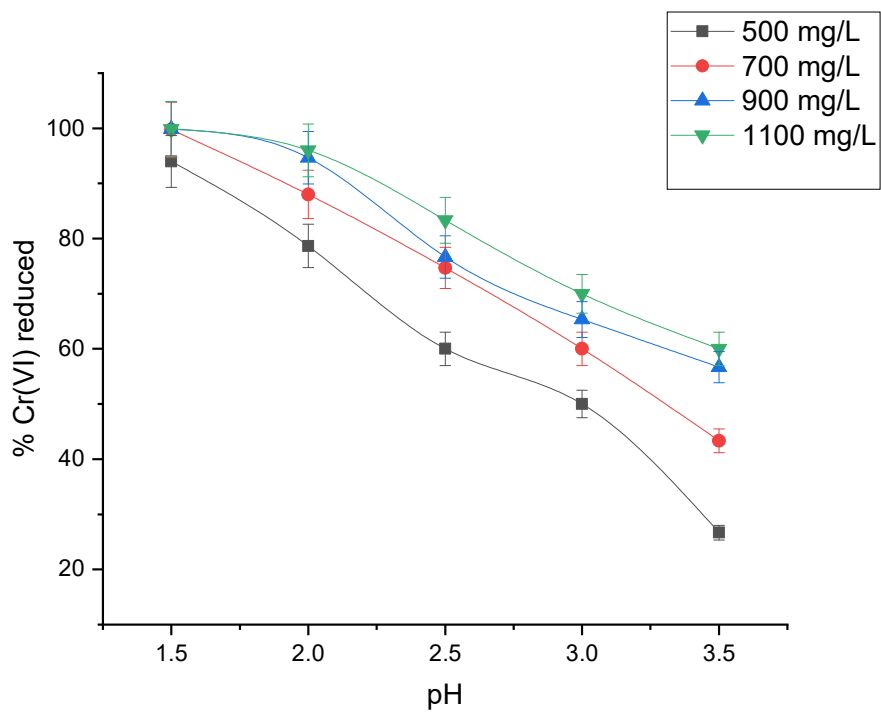

Figure 2. Effect of $\mathrm{pH}$ on reduction by ferrous sulfate. 


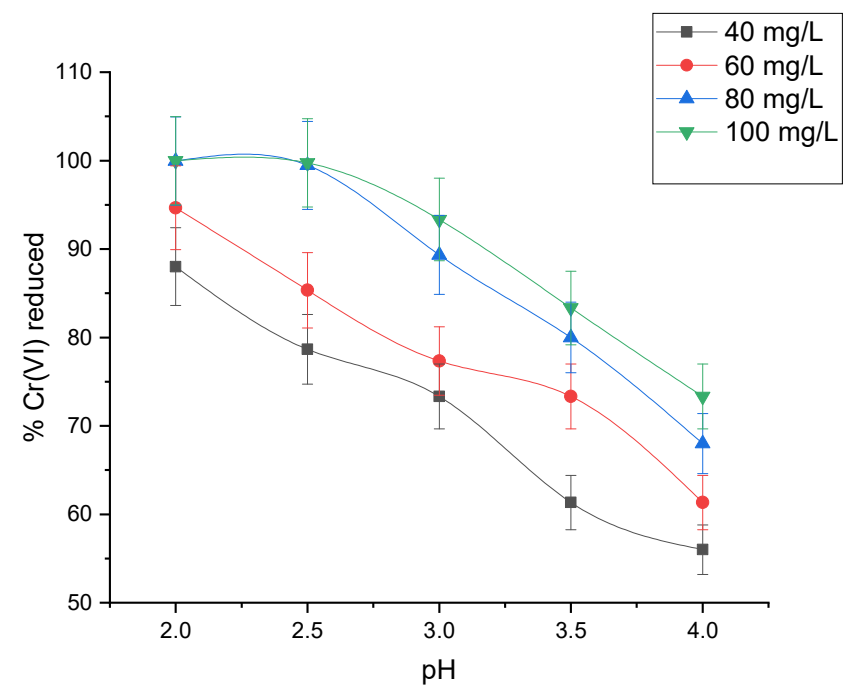

Figure 3. Effect of $\mathrm{pH}$ on reduction by sodium metabisulfite.

$\mathrm{pH}$ plays a crucial role in the reduction process. As can be seen from Figures 2 and 3, the reduction is maximum at a very low $\mathrm{pH}$ for both cases. This can be verified from the Eh-pH diagram of chromium [23], that the most prevalent form of chromium at a lower $\mathrm{pH}$ is trivalent form. Hence, it is much easier to reduce $\mathrm{Cr}(\mathrm{VI})$ to $\mathrm{Cr}(\mathrm{III})$ at a lower $\mathrm{pH}$. Also, the percent reduction increased with increasing dosages of reducing agent. This can be explained by the fact that the more reducing agent implies more possibility of collision between the substances.

After the $\mathrm{Cr}(\mathrm{VI})$ reduction, the trivalent form was precipitated in a highly alkaline medium. Figure 4, shows that the maximum removal of $98.2 \%$ was achieved by using the combination of $\mathrm{Ca}(\mathrm{OH})_{2}+\mathrm{NaOH}$.

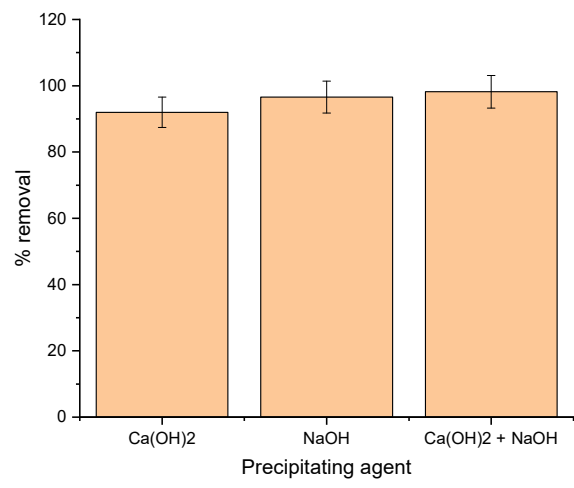

Figure 4. Removal efficiency of various precipitating agents.

Also, from Figure 5, it can be seen that the sludge generated in the case of using $\mathrm{NaOH}$ is quite high. This is explained by the fact that the sludge produced with $\mathrm{NaOH}$ is gelatinous in 
nature. However, sludge generated by using $\mathrm{Ca}(\mathrm{OH})_{2}$ is dense. Therefore, using the combination of both the precipitating agents results in a higher removal efficiency as well less volume of sludge is generated.

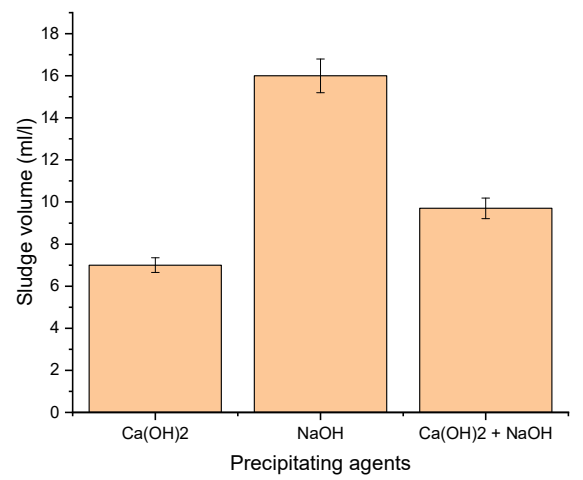

Figure 5. Volume of sludge generated.

\section{CONCLUSION}

The electroplating effluent contains a huge amount of hexavalent chromium which is quite toxic. Therefore, the reduction of $\mathrm{Cr}(\mathrm{VI})$ to $\mathrm{Cr}(\mathrm{III})$ which is less harmful is the easiest thing to do at the site. The sodium metabisulfite is a better reducing agent than ferrous sulfate for the case of $\mathrm{Cr}(\mathrm{VI})$ since the amount of reducing agent required to reduce is considerably less. It was observed that $99.86 \%$ and $99.97 \%$ of $\mathrm{Cr}(\mathrm{VI})$ was reduced by using $1100 \mathrm{mg} / \mathrm{L}$ ferrous sulfate and $100 \mathrm{mg} / \mathrm{L}$ sodium metabisulfite, respectively. The maximum reduction is achieved at a $\mathrm{pH}$ of 2. In order to precipitate the $\mathrm{Cr}(\mathrm{III})$, precipitating agents are used in alkaline medium $(\mathrm{pH}$ around 9). The best combination is $\mathrm{Ca}(\mathrm{OH})_{2}+\mathrm{NaOH}$ as the removal efficiency is maximum $(98.2 \%)$. Also the sludge generated is quite low $(9.7 \mathrm{~mL} / \mathrm{L})$. Therefore, the electroplating effluent containing huge amounts of $\mathrm{Cr}(\mathrm{VI})$ can be first treated with chemical precipitation for the most effective wastewater treatment strategy. However, in spite of its advantages, chemical precipitation requires a large amount of chemicals to reduce metals to an acceptable level for discharge. Therefore, reducing agents with the fast reduction kinetics, and the precipitating agents with less sludge production should be explored for the more efficient treatment of industrial effluent.

\section{ACKNOWLEDGMENTS}

The authors are grateful to the Department of Chemical Engineering, Indian Institute of Technology Roorkee, India for providing a platform to conduct the series of experiments and analyze the various results. Also, a special thanks to the Ministry of Human Resources and Development to provide the necessary financial support without which this work would not have been possible.

\section{REFERENCES}

1. Adekola, F.A.; Salam, N.A.; Adegoke, H.I.; Adesola, A.M.; Adekeye, J.I.D. Removal of $\mathrm{Pb}$ (II) from aqueous solution by natural and synthetic calcites. Bull. Chem. Soc. Ethiop. 2012, 26, 195-210.

Bull. Chem. Soc. Ethiop. 2020, 34(1) 
2. Kannan, A.; Thambidurai, S. Removal of hexavalent chromium from aqueous solution using activated carbon derived from palmyra palm fruit seed. Bull. Chem. Soc. Ethiop. 2008, 22, 183-196.

3. Abbas, A.; Al-Amer, A.M.; Laoui, T.; Al-Marri, M.J.; Nasser, M.S.; Khraisheh, M.; Atieh, M.A. Heavy metal removal from aqueous solution by advanced carbon nanotubes: Critical review of adsorption applications. Sep. Purif. Technol. 2016, 157, 141-161.

4. Jobby, R.; Jha, P.; Yadav, A.K.; Desai, N. Biosorption and biotransformation of hexavalent chromium [Cr(VI)]: A comprehensive review. Chemosphere 2018, 207, 255-266.

5. Raji, C.; Anirudhan, T.S. Batch $\mathrm{Cr}(\mathrm{VI})$ removal by polyacrylamide-grafted sawdust: Kinetics and thermodynamics. Water Res. 1998, 32, 3772-3780.

6. Kavita, B.; Keharia, H. Reduction of hexavalent chromium by Ochrobactrum intermedium BCR400 isolated from a chromium-contaminated soil. Biotechnol. 2012, 2, 79-87.

7. Pradhan, D.; Sukla, L.B.; Sawyer, M.; Rahman, P.K. Recent bioreduction of hexavalent chromium in wastewater treatment: A review. J. Ind. Eng. Chem. 2017, 55, 1-20.

8. Oguz, E. Adsorption characteristics and the kinetics of the $\operatorname{Cr}(\mathrm{VI})$ on the Thuja oriantalis. Colloids Surfaces A Physicochem. Eng. Asp. 2005, 252, 121-128.

9. Miretzky, P.; Cirelli, A.F. Cr(VI) and Cr(III) removal from aqueous solution by raw and modified lignocellulosic materials: A review. J. Hazard. Mater. 2010, 180, 1-19.

10. Selvaraj, K., Manonmani, S.; Pattabhi, S. Removal of hexavalent chromium using distillery sludge. Bioresour. Technol. 2003, 89, 207-211.

11. Sadrzadeh, M.; Mohammadi, T. Treatment of sea water using electrodialysis: Current efficiency evaluation. Desalination 2009, 249, 279-285.

12. Li, Q.; Zhai, J.; Zhang, W.; Wang, M.; Zhou, J. A study on adsorption of $\mathrm{Pb}(\mathrm{II}), \mathrm{Cr}(\mathrm{H})$ and $\mathrm{Cu}(\mathrm{II})$ from aqueous solution by peanut husk. Bull. Chem. Soc. Ethiop. 2008, 22, 19-26.

13. Ahmed, M.J.K.; Ahmaruzzaman, M. A review on potential usage of industrial waste materials for binding heavy metal ions from aqueous solutions. J. Water Process Eng. 2016, 10, 39-47.

14. Rengaraj, S.; Yeon, K.H.; Moon, S.H. Removal of chromium from water and wastewater by ion exchange resins. J. Hazard. Mater. 2001, 87, 273-287.

15. Gherasim, C.V.; Křivčík, J.; Mikulášek, P. Investigation of batch electrodialysis process for removal of lead ions from aqueous solutions. Chem. Eng. J. 2014, 256, 324-334.

16. Gherasim, C.V.; Mikulášek, P. Influence of operating variables on the removal of heavy metal ions from aqueous solutions by nanofiltration. Desalination 2014, 343, 67-74.

17. Mengistie, A.A.; Rao, T.S.; Rao, A.P.; Singanan, M. Removal of lead(II) ions from aqueous solutions using activated carbon from Militia ferruginea plant leaves. Bull. Chem. Soc. Ethiop. 2008, 22, 349-360.

18. Bedemo, A.; Chandravanshi, B.S.; Zewge, F. Removal of trivalent chromium from aqueous solution using aluminum oxide hydroxide. Springer Plus, 2016, 5: 1288. DOI 10.1186/s40064-016-2983-x.

19. Singanan, M.; Abebaw, A.; Vinodhini, S. Removal of lead ions from industrial waste water by using biomaterials-a novel method. Bull. Chem. Soc. Ethiop. 2005, 19(2), 289-294.

20. Kurniawan, T.A.; Chan, G.Y.; Lo, W.H.; Babel, S. Physico-chemical treatment techniques for wastewater laden with heavy metals. Chem. Eng. J. 2006, 118, 83-98.

21. Minas, F.; Chandravanshi, B.S.; Leta, S. Chemical precipitation method for chromium removal and its recovery from tannery wastewater in Ethiopia. Chem. Int. 2017, 3, 291-305.

22. Fu, F.; Wang, Q. Removal of heavy metal ions from wastewaters: a review. J. Environ. Manage. 2011, 92, 407-418.

23. Cheng, S.; Ding, Y.; Yang, C. Production processes of chromium salts. Chemical Industry Press: China; 1988; 390 (in Chinese).

24. Wang, T.; Xu, H. Reduction of $\mathrm{Cr}(\mathrm{VI})$ by hydrazine in solution saturated with $\mathrm{KHCO}_{3} . J$. Hazard. Mater. 2005, 123, 176-180. 
25. Gheju, M. Hexavalent chromium reduction with zero-valent iron (ZVI) in aquatic systems. Water Air Soil Pollut. 2011, 222, 103-148.

26. Wang, Q.; Qian, H.; Yang, Y.; Zhang, Z.; Naman, C.; Xu, X. Reduction of hexavalent chromium by carboxymethyl cellulose-stabilized zero-valent iron nanoparticles. J. Contam. Hydrol. 2010, 114, 35-42.

27. Amuda, O.S.; Amoo, I.A.; Ipinmoroti, K.O.; Ajayi, O.O. Coagulation/flocculation process in the removal of trace metals present in industrial wastewater. J. Appl. Sci. Environ. Manag. 2006, 10, 159-162.

28. Karale, R.S.; Wadkar, D.V.; Nangare, P.B. Removal and recovery of hexavalent chromium from industrial waste water by precipitation with due consideration to cost optimization. $J$. Environ. Res. Dev. 2007, 2, 209-216.

29. Wojasińska, E.; Trojanowicz, M. Ion chromatographic speciation of chromium with diphenylcarbazide-based spectrophotometric detection. J. Chromatogr. A 1996, 736, 141150 . 